\title{
Materialidade televisiva e ambiência belle époque na minissérie Mad Maria: a lógica sensorial na minissérie como dilema ${ }^{1}$
}

Solange Wajnman² e Mariana Christina de Farias Tavares ${ }^{3}$ 
A partir do estudo dos recursos expressivos da minissérie Mad Maria, tais como imagens cenográficas e figurino, pretendemos argumentar que essa produção traz, enquanto forma, elementos que apontam para a ambiguidade da visualidade televisiva. Em outras palavras, ao ilustrar paisagens românticas e impressionistas, bem como a ambiência da belle époque com suas luzes, cores reluzentes, tecidos vaporosos e cintilantes para o figurino, o dilema do meio televisivo é anunciado de maneira metafórica. De um lado, o envolvimento sensorial e a fruição estética autônoma do espectador são alavancados por esses elementos, o que favorece a mobilidade do olhar. No entanto, essa mesma condição inicial da percepção começa a se vincular a uma ordem produtiva da empresa, responsável por domesticar o olhar, inserindo-o em uma narrativa linear e em uma figurativização glamourizada.

\section{Palavras-chave}

Ambiência belle époque, cenários, figurinos, sensorialidade, midiatização. 
From the study of the expressive resources of the miniseries Mad Maria, such as scenographic images and costumes, we intend to discuss that, in its form, the production brings elements that point out to the ambiguity of television visuality. In other words, by illustrating romantic and impressionistic landscapes, as well as the belle époque ambience with all its lights, shining colors, and diaphanous and sparkling textiles to its costumes, the dilemma of the television medium is announced in a metaphoric way. On the one hand, the sensorial engagement and the spectator's autonomous aesthetic fruition are powered by such elements, which favor the mobility of the sight. On the other hand, the same initial condition of perception starts to be related to a productive order of the television business, responsible for taming the sight by inserting it in a linear plot and in a glamourized figuration.

Communication, memory, city, branding, mega events. 
Ainda que estejamos tratando da fracassada saga da construção de uma ferrovia no Brasil do início do século $X X$, em que milhares de trabalhadores foram sacrificados, o leitor deste artigo não deverá esperar encontrar aqui uma discussão acerca da questão da exploração de mão de obra ou subsídios históricos para problematizar a má gestão dos transportes no Brasil. Não dessa maneira, pelo menos. A discussão que se travará aqui, e que é fruto de uma investigação mais ampla, está atenta à visualidade do livro Mad Maria, escrito em 1980 por Marcio de Souza e reconfigurado para a televisão como minissérie da Rede Globo, em 20054.

Concebida como um grande projeto cenográfico e tecnológico, a elaboração dessa minissérie, com lances espetaculares como a presença física da própria locomotiva, o espaço da selva amazônica e efeitos especiais complexos (o decepar de mãos de um índio ou a cabeça de um trabalhador), consagrava em 2005 a força videográfica da Rede Globo de Televisão.

Estamos interessados aqui em abordar questões ligadas à percepção e à materialidade do corpo, sobretudo a partir do contexto dessa produção audiovisual. É importante ressaltar que aquilo que se apresenta como novidade na imagem videográfica é a ambiência da belle époque urbana e seu esplendor. Aquilo que no romance é colocado de maneira incipiente, em breves passagens, torna-se um protagonista importante quando transmutado para a representação videográfica. Em outras palavras, observamos que a ambiência da modernidade com seus espaços, luzes, cores, formas e texturas do vestuário é plenamente instaurada nessa minissérie da Rede Globo. Essa é pura presença.

Diante dessas questões, estamos interessados em propor aproximações entre esta ambiência visual do ponto de vista da genealogia do suporte televisivo e das imagens, cenários e figurinos elaborados pela direção de arte. Na verdade, estamos trabalhando dentro do campo mais amplo da história da imagem e da 
percepção, o que significa dizer, mais especificamente que nos movemos aqui entre as congruências da televisão e as expressões tecnológicas e artísticas do século XIX. Assim, não seria descabido propor a ideia de que a minissérie desencadeia um tipo de sensorialidade visual e tátil, a exemplo do homem da modernidade. Isto significa dizer que o telespectador captaria a ambiência visual a partir do jogo rítmico e fragmentado de fitas, laços, gases, flores, espelhos e brilhos da ambiência da belle époque, que parecem ter saído das descrições cinéticas de um Baudelaire ou João do Rio. Efeitos criados pela direção de arte e que proporcionam uma disseminação do olhar tal como o observador do século XIX. Perguntamos ainda se este olhar tátil e singular não seria capturado e domesticado pela lógica produtiva da emissora.

Assim, retomando e aprofundando a problemática podemos dizer que por um lado, o telespectador da minissérie pressupõe um olhar à maneira do observador do século XIX. É ele, como observa Benjamin (apud CRARY, 2012):

um observador ambulante, formado por uma convergência de novos espaços urbanos, novas tecnologias e novas funções econômicas e simbólicas das imagens e dos produtos-formas de iluminação artificial, novos usos e espelhos, arquitetura de vidro e aço, ferrovias, museus, jardins, fotografia, moda, multidões. (p. 28).

Ressalta-se, nesse contexto, a própria questão da construção de uma estrada de ferro, o que, inclusive, a minissérie problematiza. Tratava-se da necessidade do transporte de matérias-primas e mercadorias e da circulação entre o espaço urbano e o rural. Assim, logo no início do século XX, Farquhar, empresário americano, está interessado em explorar as possibilidades do Brasil, novo polo investidor. Uma ferrovia que pudesse exportar a borracha do Brasil, como também da Bolívia, conciliaria seus interesses com a política exterior brasileira da época. Ora, esta seria a lógica dos empreendimentos, da industrialização proposta pela modernidade. E é neste contexto de circulação de tempo, espaço e produtos que a percepção se modifica. 
Trata-se de uma época em que os novos empreendimentos do capitalismo, tais quais a circulação ferroviária, poderiam proporcionar "um desmoronamento das distâncias e uma nova experiência do corpo e da percepção do ser humano, moldada pela viagem a novas velocidades e por novos e atraentes potenciais de perigo." (GUNNING, 2001, p. 40).

Da mesma forma, Crary observou uma condição do olhar em que a percepção é nitidamente "temporal e cinética", afirmando que "jamais há acesso puro a um objeto puro em sua unicidade". A visão seria sempre "múltipla, contígua e sobreposta aos outros objetos desejos e vetores." (CRARY, 2012, p. 28).

E é dessa maneira que propomos aqui a ideia de que essa percepção encontra seu equivalente na movimentação do olhar do telespectador em direção à sucessão de vestidos com cores variadas, texturas, rendas, plumas, gazes e pérolas que compõem as diversas sequências. Trata-se de uma circulação de objetos de moda.

Ao mesmo tempo, ressaltamos as paisagens de água, sol e vegetação que se exibem de maneira romântica, e por vezes impressionista, a julgar pela decomposição da figura. Do ponto de vista do campo de estudos da visualidade em seus aprofundamentos sobre tecnologias ópticas e imagens pictóricas (COUCHOT, 1988; MACHADO, 1990), de alguma maneira podemos supor que estes processos, sobretudo a questão da composição das paisagens, são coincidentes com a própria estrutura videográfica. Podemos relacionar a gestalt do impressionismo e, principalmente, a do pontilhismo, em suas técnicas de decomposição da luz e de divisionismo das formas com a configuração visual da televisão. A imagem figurativa foi sendo substituída por pequenos retângulos ou pontos coloridos a ponto de ser dissolvida numa rede de retícula granulosa. Caberia ao espectador, assim como àquele que contemplava o quadro de Seurat ${ }^{5}$, sintetizar em seu próprio aparelho perceptivo estes estilhaços de imagem em numa gestalt inteligível, como observa Machado (1990, p. 45). 
Todas essas experiências no campo da arte coadunam-se com as experiências de desenraizamento do tempo e do espaço próprias do homem da modernidade. Além da problemática em torno da estrada de ferro, destaca-se também a questão da moda enquanto circulação e fluxo de signos exagerados. Justamente em um momento de maior expansão de capital na Europa, e depois no Brasil, a moda assume proporções importantes na vida social. Como lembra Crary (2012), a modernidade destaca uma desestabilização e uma mobilidade crescentes dos signos e códigos que tem início no Renascimento. Antes, tais signos estavam enraizados em posições relativamente seguras no interior de hierarquias sociais fixas. Em uma sociedade que se moderniza com maior mobilidade de classes, tal qual esta do final do século XIX e início do XX, observase a velocidade dos signos de moda. Pode-se pensar que a modernidade seria "uma proliferação de signos sob demanda" (Ibid., p. 20). E, nesse contexto, as ideias de volatilidade, ou de caleidoscópio, expressas por Baudelaire, e mesmo mais tarde no Brasil por João do Rio, fazem sentido. Essas inspirações cabem no trato da configuração de arte da minissérie, como mostraremos adiante.

Por outro lado, há que se pensar como esta ambiência visual da belle époque, que mais se assemelha às condições epistemológicas e institucionais do homem da modernidade, é atualizada e reconfigurada para o homem de 2005, época de exibição da minissérie. Como essa experiência será realocada para a contemporaneidade com uma produção televisiva às vésperas do padrão digital e de alta definição?

Há que se considerar que, se a experiência de um olhar desprovido de referências estáveis já exigia forças reativas na modernidade, o que se pode esperar de um momento considerado por muitos como uma modernidade tardia ou ainda como uma pós-modernidade? Ora, já no século XIX, observouse a construção de um regime de normatização a partir da descentralização e dispersão do olhar, como mostram alguns autores como Foucault para os sistemas jurídicos e institucionais e Crary (2012) para a experiência do homem urbano, que escreve: 
[...] a essa dissolução final de uma fundamentação transcendente para a visão emerge uma pluralidade de meios para recodificar a atividade do olho, ordená-la, elevar sua produtividade e impedir sua distração. Com isso, os imperativos da modernização capitalista, ao mesmo tempo que demoliram o campo da visão clássica, geraram técnicas para impor uma atenção visual mais acurada, racionalizar a sensação e administrar a percepção. Trata-se de técnicas disciplinares que solicitaram uma concepção de experiência visual como algo instrumental, modificável e abstrato, e que jamais permitiram que um mundo real adquirisse solidez ou permanência. (p. 32).

Sabemos que a televisão vem sendo modificada desde sua configuração original. Do conceito de um mosaico eletrônico com poucos pontos de informações passamos para uma televisão digital de alta definição. O que seria constitutivo da natureza dessa primeira televisão seria a baixa definição da imagem, o que dificultaria o uso de cenários excessivamente detalhados, e a precariedade de profundidade de campo que limitaria as paisagens amplas e abertas. Acrescente a isso a tomada de cena por várias câmeras, que, de maneira muito prática, recortavam e a fragmentavam a imagem para facilitar sua edição, muitas vezes simultânea. Poderíamos também pensar que a estrutura da primeira televisão assemelhava-se à estrutura de colagem enquanto procedimento estético das últimas correntes do pensamento estético: materiais heteróclitos e fragmentados que se compilam pela ação do olhar do editor de imagens e do telespectador.

Em 2005, época em que a minissérie é exibida, a noção de linearização já se torna muito mais recorrente pela diferenciação que esse tipo de produto tenta estabelecer em relação à telenovela. Menos cortes, maior presença de planos panorâmicos e sequenciais à semelhança da linguagem cinematográfica, mais detalhes em cenários e figurinos e, sobretudo, a força da nitidez de uma televisão de alta definição, começam a definir um novo padrão de qualidade. Acreditamos residir aí, nesta configuração complexa, a problemática ou o dilema da visualidade da TV. A figura do flaneur como um "distraído consciente", que poderia ser imputada aqui ao telespectador ao se articular sensoriamente com essa estética, parece estar ameaçada. 
Outro fator que contribui para a normatização desse olhar distraído do telespectador - o flaneur - é a condição de midiatização que os produtos televisivos se encontram. Assim é que esta experiência, distante ao nosso tempo, pode ser atualizada para uma imagem abstrata próxima ao estereótipo. Trata-se da própria condição de um meio de comunicação, como a televisão, que precisa agregar audiências heterogêneas de tempos e espaços diferentes. Para Braga (2007), a lógica da midiatização supõe alguns mecanismos: rapidez nas comunicações, abrangência geográfica e populacional, captação, objetivação, transformação, transmissão e circulação de tipos de informações e comportamentos, e a possibilidade de usá-los diretamente em interações sociais. É nesse contexto que a circulação ampliada e descontextualizada das imagens e/ou sons, objetos e situações podem normatizar uma referência histórica. A glamourização construída pela direção de arte contribuiria para esse processo. Enfim, deixamos como problemática a ideia de que essa minissérie apontaria para um dilema entre a própria natureza material da televisão original (sincrética, híbrida, heteróclita) e suas formas de linearização e domesticação do olhar.

\section{As imagens picturais na minissérie e experiências sensórias}

Ainda nas primeiras décadas do século XIX, antes mesmo da invenção da câmera obscura e da fotografia, a proliferação de tecnologias tais como o taumatrópio, fenacitoscópio, diorama e o estereoscópio, criou um observador com variadas experiências ópticas e sensoriais. Junte a isso o dinamismo da arte desse século, que modificou as formas e os modos de visualidade. Ainda que possa haver ambiguidades e descontinuidades nesse caminho epistemológico do observador, como demonstra Crary (2012), o resultado foi um "um colapso dos modelos clássicos e seu espaço estável de representações." (p. 32). Para ele, "a observação torna-se cada vez mais, uma questão de sensações e estímulos equivalentes, desprovidos de referência espacial" (loc. cit.).

A televisãosurge como um dosresultados desseprocesso. Atérecentemente, por conta de sua baixa definição, emitiam-se imagens por fragmentos e fluxos, 
e os elementos figurativos eram percebidos pelo telespectador a partir de um esforço de síntese. Estamos muito mais próximos de uma imagem de colagem e de pulsação das experiências ópticas e sensoriais da modernidade. Até pouco tempo atrás não se tratava ainda de uma imagem de profundidade. Essa só viria mais tarde, a partir dos anos 90. A minissérie qual tratamos parece ter dado um grande passo nessa direção, como atestam não só seus planos em aberto, mas também a variedade de imagens sequência.

Aliada a essa precariedade da profundidade de campo, evitava-se, em grande parte das telenovelas, o aproveitamento de quadros abertos e a ocorrência de paisagens amplas. O recorte era fragmentário e fechado; os primeiros planos, com sequências de diálogos em ambientes fechados, eram prioritários. Chama-nos atenção, nesse contexto, o caráter fragmentado e a construção em mosaico, tanto do ponto de vista das condições tecnológicas do suporte, como da própria narrativa seriada estruturada por pequenas sequências em partes e interrupções. Podemos supor aqui um processo em continuidade entre a televisão e as experiências ópticas e sensoriais da modernidade.

Em 1990, a novela O Pantanal, da Rede Manchete de Televisão, marca uma diferença nesse padrão, já que há a tomada de planos abertos ou panorâmicos, e câmeras mais potentes começam a modificar a qualidade da imagem. Em 2005, Ruy Barbosa, autor de Mad Maria, aprimora seu estilo na Rede Globo, trazendo uma variedade de cenas na selva, em que o telespectador acompanha os longos planos sequenciais à maneira linearizada da linguagem cinematográfica. Tratase do desenvolvimento de um caminho para a televisão digital de alta definição que, de maneira ainda mais sistemática, começa a se consagrar no Brasil. A penetração do vídeo na selva amazônica, a reconstrução de trechos da ferrovia, a reciclagem da locomotiva e principalmente a captação de imagens com alta qualidade, inclusive de um ponto de vista pictórico, são provas inegáveis da qualidade tecnológica da época que marcaria um novo padrão audiovisual.

A visualidade de Mad Maria, a nosso ver, combina esses dois padrões. Um primeiro baseado em um modelo que pressupõe recursos cognitivos e sensórios 
de uma percepção fragmentar e outro, de uma atenção mais passiva e linearizada. Ainda assim, esse fato não seria específico dessa minissérie, pois a requintada produção de Os Maias também traz, embora em menor escala, esse tipo de aproximação. O que é específico é o fato da primeira apresentar, além dessa marca, uma coincidência em termos narrativos com a própria questão da modernidade: as novas e possantes máquinas, locomotivas, a efemeridade. Tais elementos são simultâneos às novas maneiras de percepção, como descrevemos acima, compondo um momento privilegiado para apreendermos essa visualidade ambígua.

Dessa forma, ao investigar o trabalho da direção de arte, no que diz respeito às fotografias, cenários e figurinos colocados em imagem, desenvolvemos neste paper alguns argumentos que corroboram essa proposição.

Detenhamo-nos, por exemplo, na questão das imagens com qualidades pictóricas à maneira do romantismo e do impressionismo que surgem diversas vezes na minissérie. Há uma variedade de paisagens captadas em longos planos panorâmicos que lembram pintores como Turner. Como em Turner, essas imagens-pintura detém certa abstração e volatilidade da forma em direção aos elementos da natureza. Observa-se ainda a expressividade desses elementos, seja a água em sua continuidade com a atmosfera, um pôr do sol transformando figuras humanas em vultos, seja a água como um tufão irrefreável que não se submete ao barco ou à personagem.

Trata-se, antes de tudo, de uma fusão. E será assim também, nessa sintonia da fusão, que uma locomotiva envolta em seu vapor ou que sua fornalha vão surgir em vários momentos. Qualquer semelhança com o título das obras de Turner ${ }^{6}$, como em "Chuva, Vapor e Velocidade", não nos parece mera semelhança, ainda que tal efeito possa ter sido criado de maneira não intencional pela direção de arte. Há uma lógica interna. De fato, há uma tendência para grandes planos dentro dos quais elementos da natureza e da civilização possam ser dissolvidos ou confundidos. 
Ora, estamos diante da postura de um romântico. De maneira geral, podemos dizer que, desde o romantismo, o sujeito já perde a referência estável da perspectiva linear e do objeto estável externo a si mesmo. O romântico sente as coisas do interior, como se elas difundissem uma corrente, um fluxo perceptível (COUCHOT, 2012, p. 88).

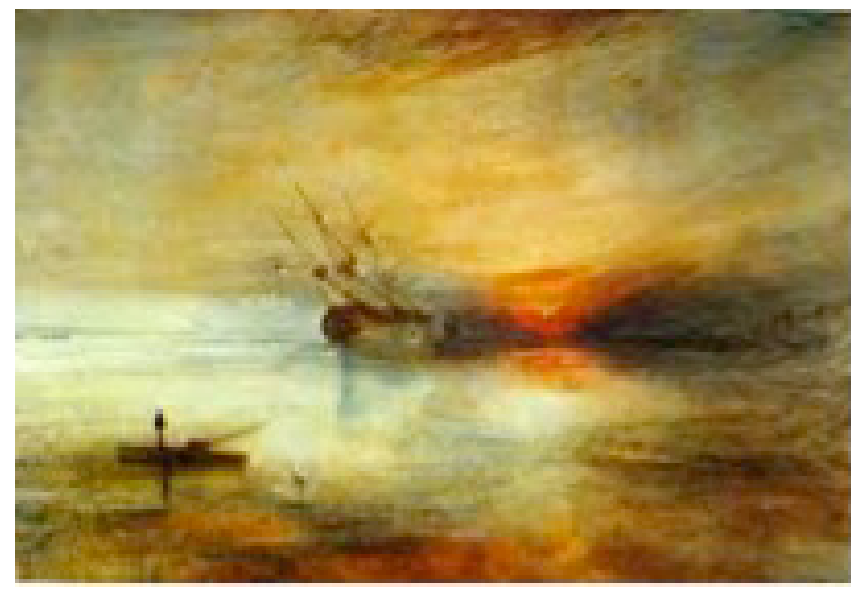

Figura 1: Fort vimieuex (TURNER, 1831)

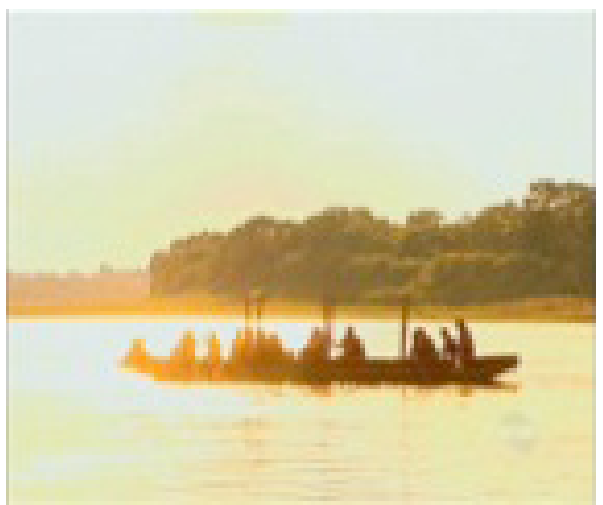

Figura 2: Trabalhadores no barco (MAD MARIA, 2014)

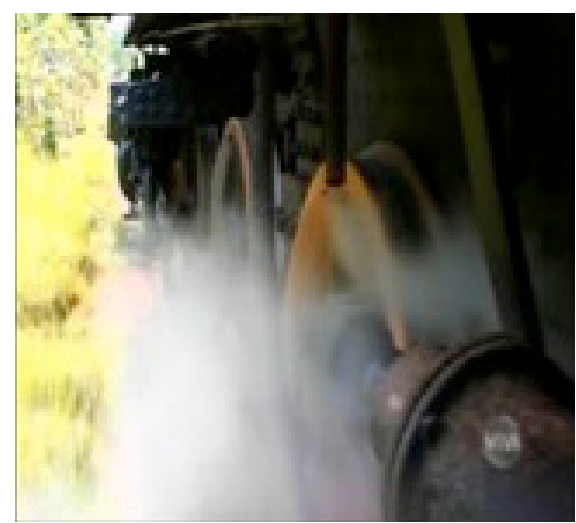

Figura 3: Locomotiva (MAD MARIA, 2014) 


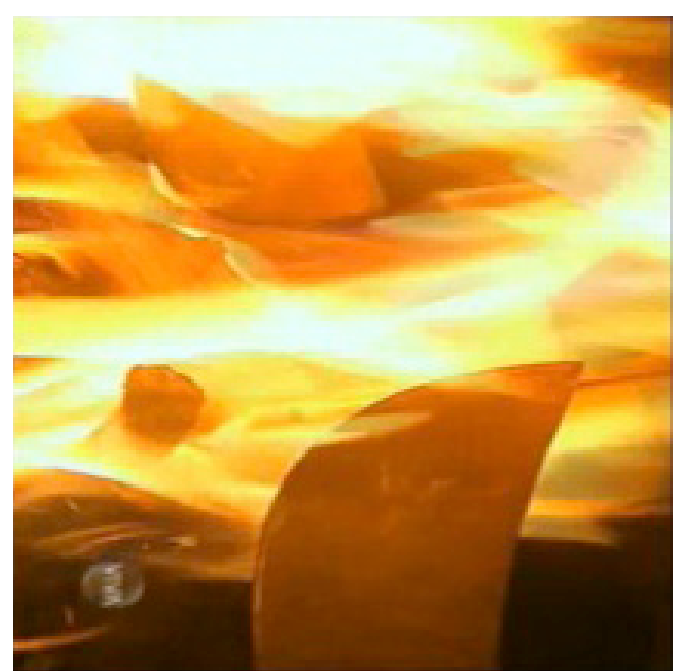

Figura 4: Detalhe da fornalha da locomotiva (MAD MARIA, 2014)

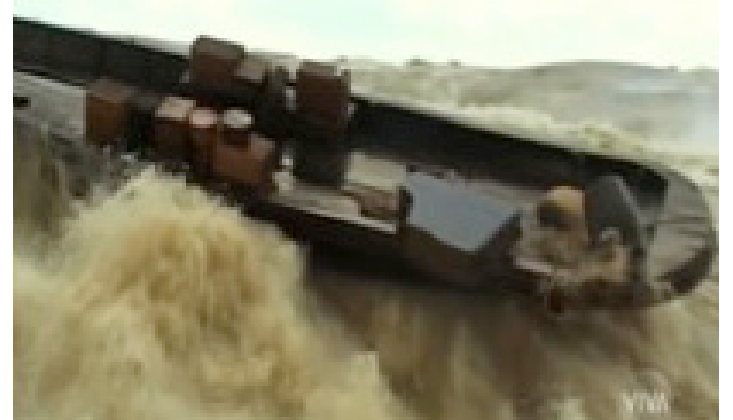

Figura 5: Naufrágio do barco (MAD MARIA, 2014)

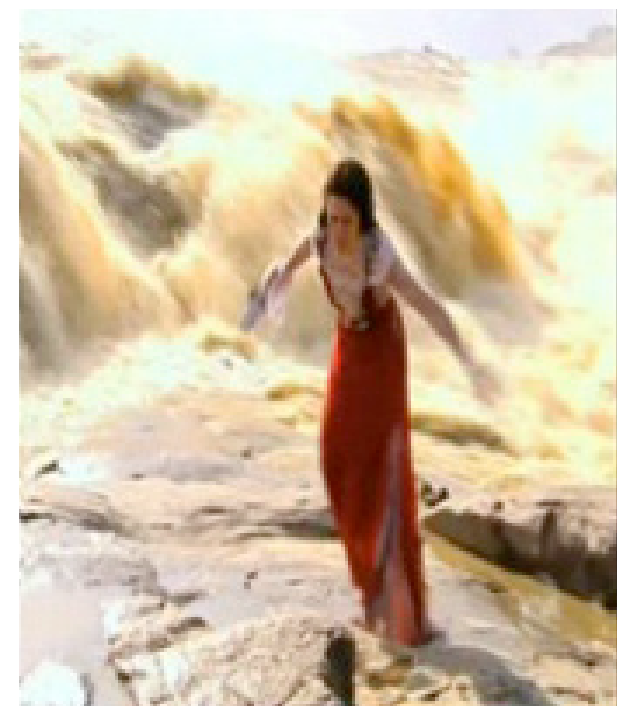

Figura 6: Consuelo e o naufrágio (MAD MARIA, 2014) 
Para o romântico e o impressionista, o olho não capta as formas dos objetos perfeitamente estáveis, mas em constante transformação. O olho é um motor informacional que passeia pelos contrastes, pelas diferenças entre as cores e as fontes cromáticas. Nesse contexto, as imagens impressionistas são um trabalho de decomposição de cor. Novamente encontramos semelhanças entre imagens artísticas da época e imagens da minissérie. Nesse caso, uma imagem clássica de Monet.

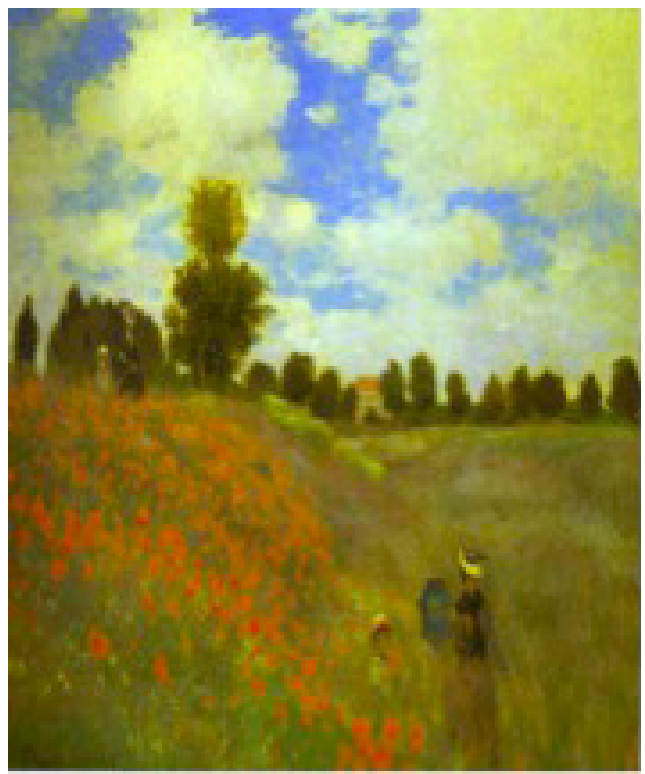

Figura 7: Campo de papoulas (Monet, 1873)

Figura 8: Consuelo e Dr. Finnegan no campo (MAD MARIA, 2014) 
É interessante perceber que a televisão apresenta essas "reproduções" dentro de uma estrutura videográfica de alta definição, de sequências contínuas e em planos de longa duração. Apresenta de forma linearizada aquilo que os movimentos artísticos haviam proposto como fragmentado e descontínuo.

A experiência sensória impressionista também pode chegar de maneira literária. Ela existe em certos depoimentos da época, como aqueles do cronista João do Rio, cuja abordagem impressionista parece relatar a experiência de um olho que se dispersa por vários elementos. Dentro do conjunto de referências da época, a partir das quais a direção de arte se inspira, podemos crer que se encontram aí essas descrições, conhecidas justamente por expressarem a ambiência da belle époque no Rio. Tratam-se de impressões recolhidas por alguém que deambula na cidade e registra elementos fragmentados e descontínuos.

Na minissérie, a imagem da chegada da comitiva do Rio de Janeiro em Porto Velho parece ter saído de uma das descrições de João do Rio sobre as telas de Eugênio Latour, ou das descrições das atrações coloridas que compunham a Exposição Universal no Rio de Janeiro. Encontramos, nessa imagem-pintura em plano aberto, uma mistura suave de tons e cores advindos de roupas, malas, chapéus, fitas, serpentinas e do próprio navio que atraca.

As mulheres, em sua maioria, estão completamente trajadas com vestidos, luvas, maletas ou bolsas, chapéus, usando tons claros ou pastéis. Entre elas, Tereza, a amante do empresário Farqhar, se diferencia pelo seu vestido cor de tangerina. Um vestido vaporoso e repleto de panos que se mexem onduladamente com seus movimentos e com a brisa. Os homens vestem tons mais claros do que o padrão habitual para o século XIX. Mas importa ressaltar aqui que, à maneira impressionista, a cartela de cores se confunde em tons que se espalham e combinam: o fundo do casco preto do navio contrastando com a terra do chão, que se espelhanas camisas de tons terrosos dos integrantes da comitiva, em um vestido vermelho e na sombrinha dourada de uma das convidadas, culminando no laranja tangerina de Tereza. Estamos diante de elementos de cor que se fusionam. 


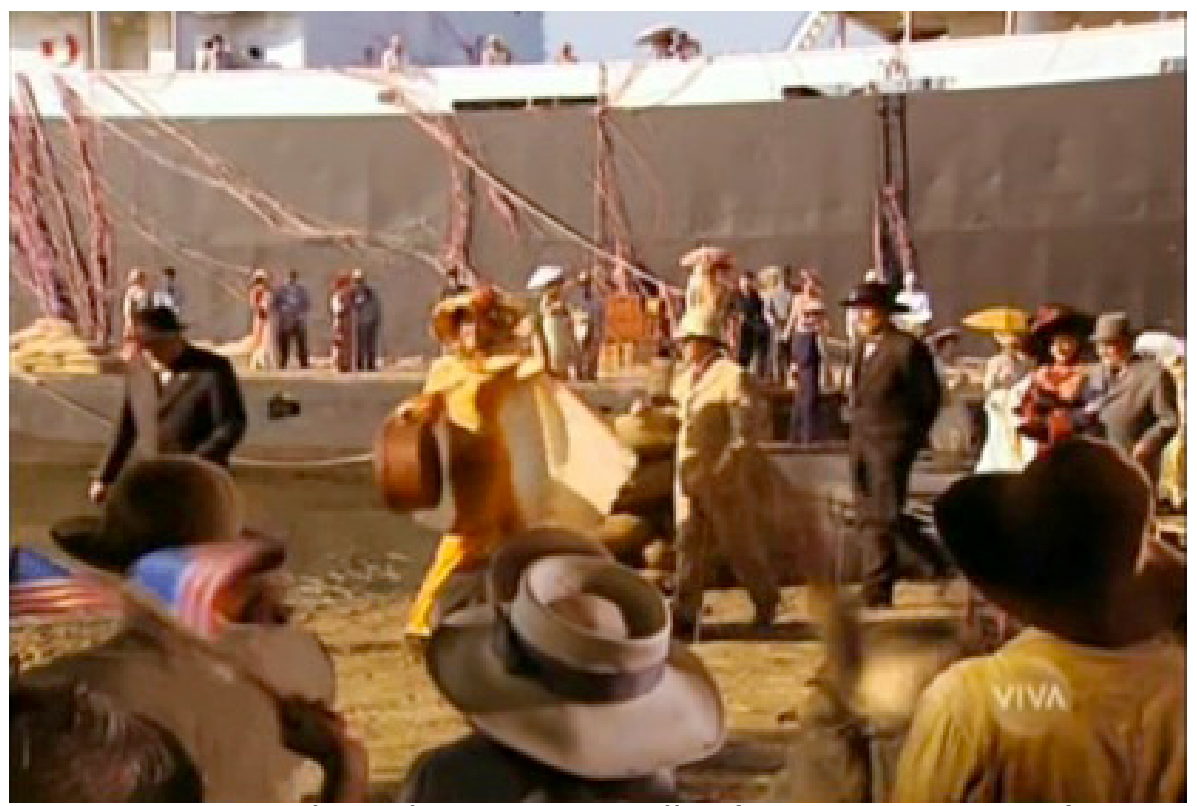

Figura 9: Chegada em Porto Velho (MAD MARIA, 2014)

\section{Ambientação e figurino enquanto experiência sensória e óptica}

Pode-se entrever o diálogo entre cronistas, escritores, pintores e escritores da época com a direção de arte para a construção do ambiente belle époque. Assim é que, as crônicas dos jornais e das revistas semanais (como FonFon e $A$ Semana), as imagens fotográficas desses periódicos, dos álbuns particulares, e até mesmo de alguns filmes, compõem a leitura visual da época.

Com a ambientação de rua que compõe as cenas externas, constata-se os legados de fotógrafos como Augusto Malta e Marc Ferrez. Essas imagens são preciosas para a composição dos mais diversos tipos de personagens. Isso fica visível na primeira cena da personagem Luiza que, sonhadora, observa a rua de Mata Cavalo, postada diante da venda dos pais, onde trabalha. Observa-se a rua movimentada e a passagem de dois vendedores de aves, cada um com uma vara ao ombro, equilibrando dois cestos cheios dos animais. O telespectador pode desconhecer, mas ele está sendo transportado para a série de fotografias de Marc Ferrez sobre os trabalhadores do Rio, onde existem imagens de negros, mulatos e macucos carregando o mesmo tipo de artefato e vendendo uma variedade de mercadorias. 
Em A Alma Encantadora das Ruas (Rio, 2008), João do Rio narra os tipos que frequentavam as diversas zonas da cidade do Rio de Janeiro; narra um Rio que sai de dentro de casa para aparecer nas ruas, principalmente depois da abertura da Avenida Central, onde o trottoir, em suas idas às confeitarias Cavé e Colombo, na Rua do Ouvidor, e suas vitrinas, as companhias musicais do Teatro Lírico eram atração. Soma-se a isso a profusão dos meios de transporte que conviveram simultaneamente: os tílburis, os bondes e os novíssimos automóveis. A luz elétrica deixava a cidade mais segura, sem tantas áreas de sombra, então a população dos cantos do Flamengo Botafogo e Catete podia se deslocar sem muito medo.

Da venda do pai de Luiza, provavelmente na região da Rua de Mata Cavalos, parte velha e pobre da cidade, pode-se avistar um quiosque, elemento comum na cidade, lugar de reunião de um grupo masculino de camada popular. Em seus textos, João do Rio (2008) sempre faz alusão aos quiosques como parte da paisagem urbana carioca:

\begin{abstract}
Tínhamos parado à esquina da Rua Fresca. A vida redobrava aí de intensidade, não de trabalho, mas de deboche. Nos botequins, fonógrafos roufenhos esganiçavam canções picarescas; numa taberna escura com turcos e fuzileiros navais, dois violões e um cavaquinho repinicavam. Pelas calçadas, paradas às esquinas, à beira do quiosque, meretrizes de galho de arruda atrás da orelha e chinelinho na ponta do pé, carregadores espapaçados, rapazes de camisa de meia e calça branca bombacha com o corpo flexível dos birbantes, marinheiros, bombeiros, túnicas vermelhas e fuzileiros uma confusão, uma mistura de cores, de tipos, de vozes, onde a luxúria crescia. (p. 7).
\end{abstract}

Tratava-se da região da Rua de Mata Cavalos, que ainda não estava no traçado da Avenida Central desenhada por Pereira Passos: "Toda essa parte da cidade, uma das mais antigas, ainda cheia de recordações coloniais." (RIO, 2009, p. 30).

Homens e mulheres trafegam em número pelas ruas do centro, sendo a Rua do Ouvidor a mais famosa. É dia e a senhora em primeiro plano está 
corretamente vestida com uma roupa clara. Os homens usam fraques (morning coats), sobrecasacas, e até paletós mais curtos, com seus chapéus de palinha e/ ou de estilo bowler. Ressalta-se a simultaneidade do uso de tílburis, carruagens, e os novos modelos de carros importados, todos engarrafando as ruas transversais do centro, que não haviam sido feitas nem para esse tipo, nem para essa quantidade de meios de transportes.

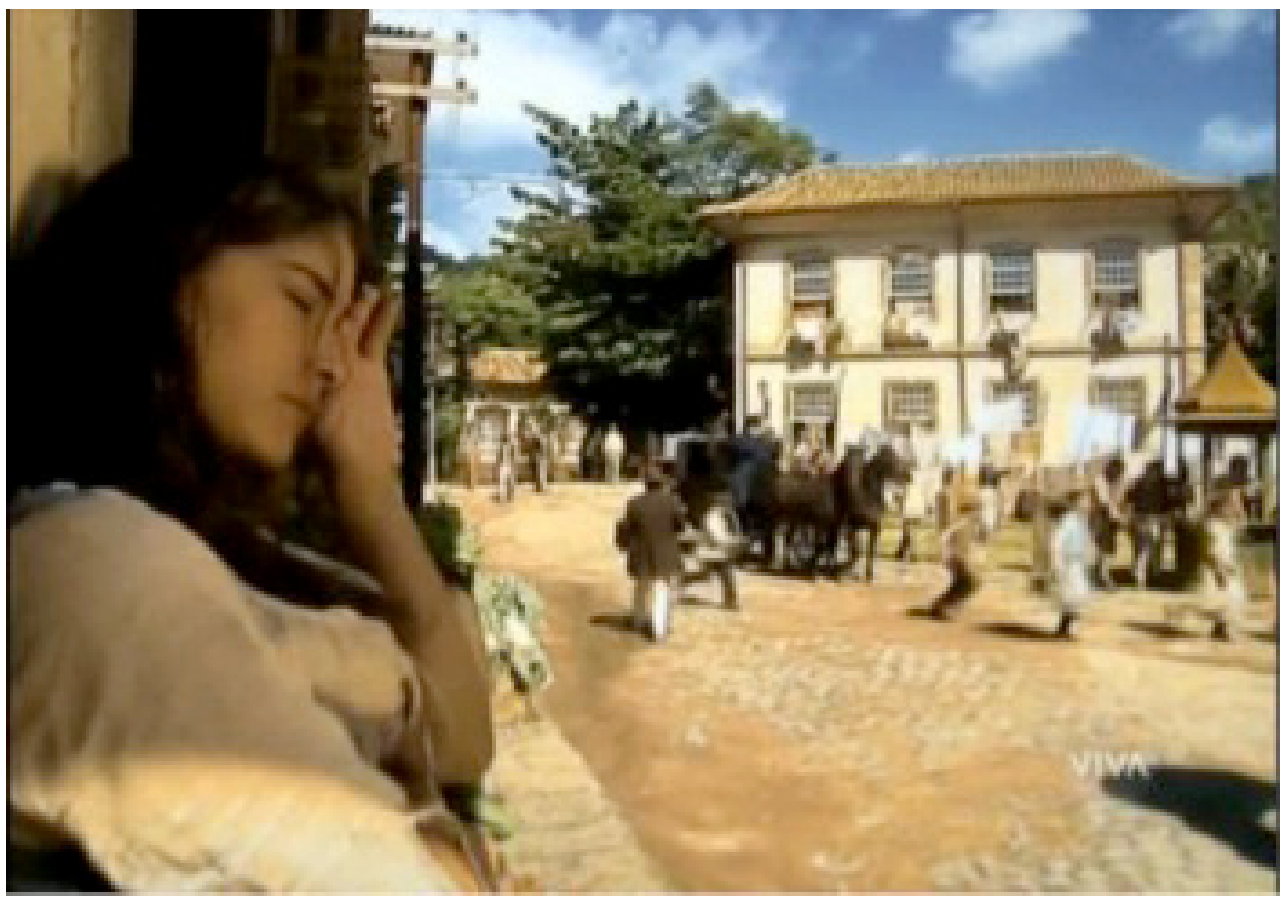

Figura 10: Vista do quiosque a partir do bar do pai de Luiza (MAD MARIA, 2014)

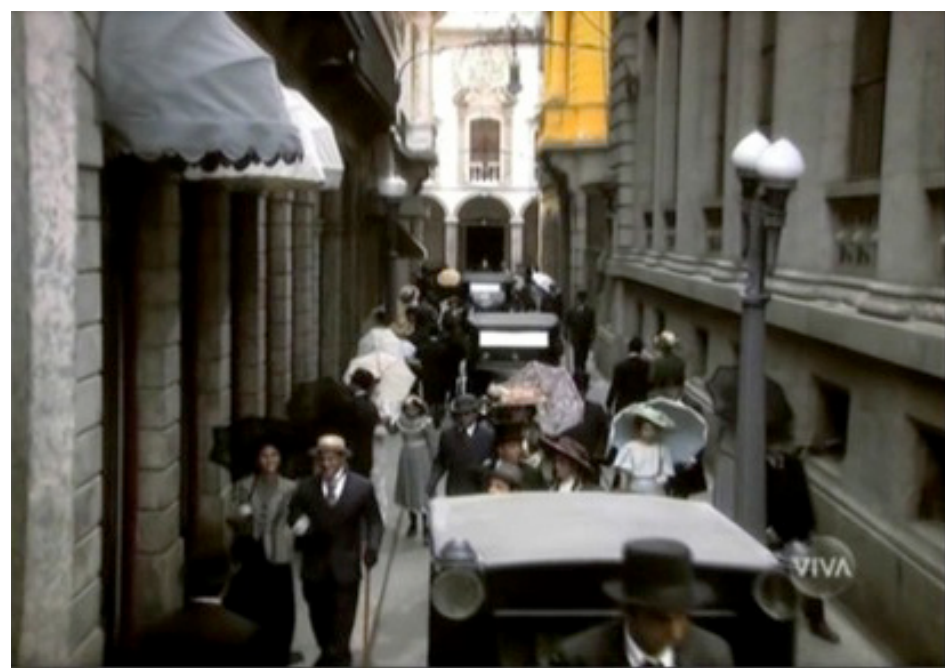

Figura 11: Rua com passantes (MAD MARIA, 2014) 
Acrescenta-se a essas cenas externas a Confeitaria Colombo ou o velho casarão do Ministro. No entanto, é importante ressaltar aqui que a minissérie privilegia as cenas internas em plano médio ou em close de ambientes fechados. A trama do núcleo urbano transcorre na maior parte das vezes em gabinetes, quartos, salas de estar e jantar. Trata-se, como observamos anteriormente, da combinação de um primeiro modelo de televisão composto por cortes fragmentados e sequências interrompidas. Modelo ainda bastante recorrente nas telenovelas, mas que se aprimora em função da definição da qualidade da imagem digital, apresentando, inclusive, detalhes desses objetos e roupas. Sem profundidade e sem planos abertos, a câmera pode se deter nos objetos situados na superfície.

É nesse contexto que o olho é captado pela flutuação da câmera e deambula pelo fluxo de elementos que saltam do vestuário à decoração. O luxo da belle époque flutua através da câmera que sonda em momentos descontínuos os vidros, as pratarias, as rendas, os véus e as finas mousselines. Soma-se a isso os papéis de parede e os sofás estofados de veludo.

A busca de verossimilhança na riqueza dos detalhes dos ambientes é notória. Nota-se que a produção da minissérie chegou ao paroxismo de utilizar em cena um abajur estilo Tiffany. O modelo famoso de mosaicos de vidros coloridos adorna a sala e o quarto da Sra. Castro. Na mesa do gabinete do empresário americano, Farqhar, encontramos o modelo bankerlamplight, um abajur de cúpula verde que entrou em produção nos EUA em 1867. Ao fundo de sua sala, dois abajures de múltiplas cúpulas, estas seguras por um homem de ferro ou bronze com os braços erguidos, servem não só para a sua função, iluminar, mas também para enfeitar, caracterizando o excesso de objetos industriais decorativos da burguesia emergente, algo tão contestado por William Morris.

Na sala de jantar da casa dos Castro, observamos um conjunto de cadeiras Dom José I, do século XIX. O cômodo era todo atapetado, com várias mesas de canto e mesas de chá. As colunas, que se assemelham ao mármore, podem ser apenas objetos de decoração e falsamente revestidas do material desejado 
- seja de mármore, de ônix ou de ágata, etc. Sabe-se que, nos catálogos do século XIX, as colunas e até os revestimentos de colunas eram vendidos. Além das mesinhas de canto e centro já citadas, ao fundo vemos uma cortina de veludo finalizada com bordas. Sob essa cortina mais pesada, havia outra de renda branca, mas leve e fresca. No geral, a minissérie usa cortinas de veludo em todos os ambientes domésticos mais luxuosos. O cenário a seguir é apenas um exemplo.

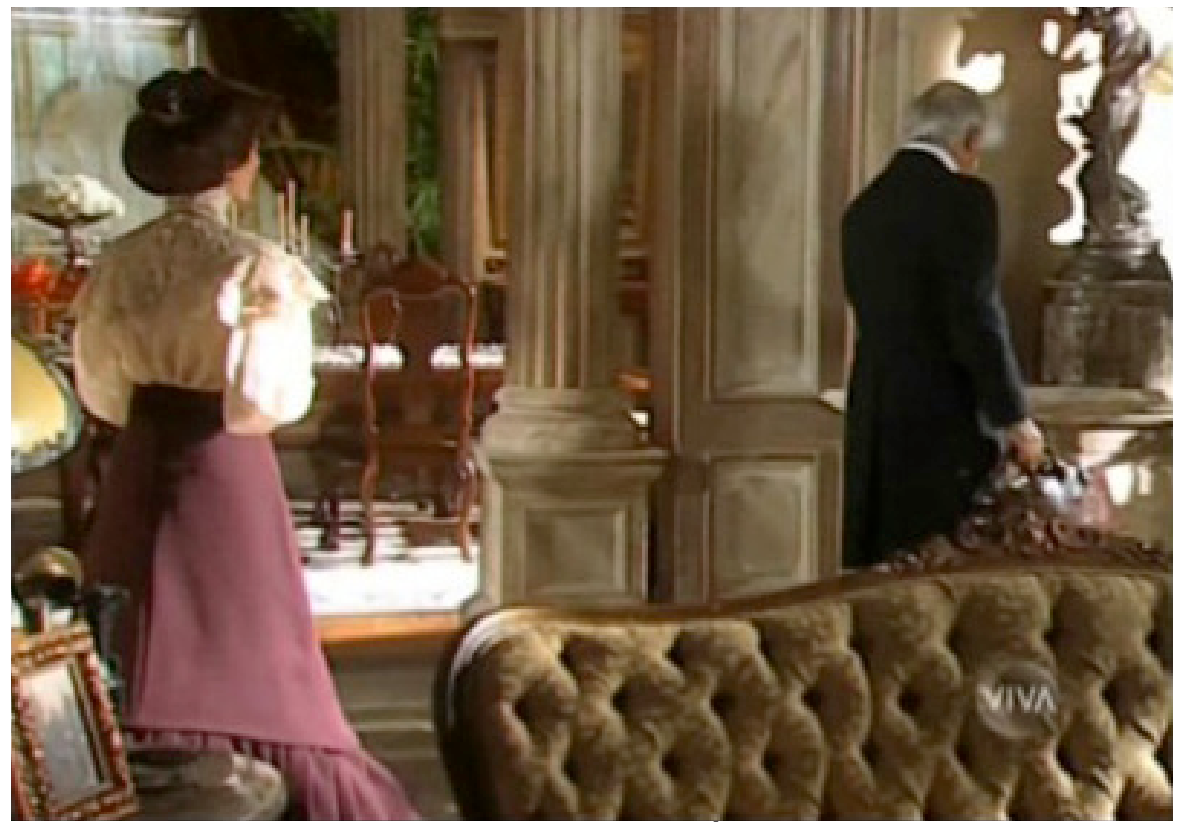

Figura 12: O casal Castro em sua residência (MAD MARIA, 2014)

Em outro ambiente, a sala de jantar do navio que recebe os convidados em viagem para Porto Velho, também percebemos o mesmo tipo de excessos. Trata-se de um espaço fechado ricamente decorado, com candelabros de prata, um buffet com peças de prata, porcelana e cristal. Nas paredes, entre painéis de madeira, pinturas podem ser vistas, mas não decifradas pelo telespectador, glamourizando o salão, assim como uma balaustrada de metal dourado que cerca todo o espaço, dividindo o ambiente em um plano mais alto e outro mais baixo. A luz difusa e as cortinas entre o dourado e o mostarda contribuem para dar um ar resplandecente ao ambiente. 


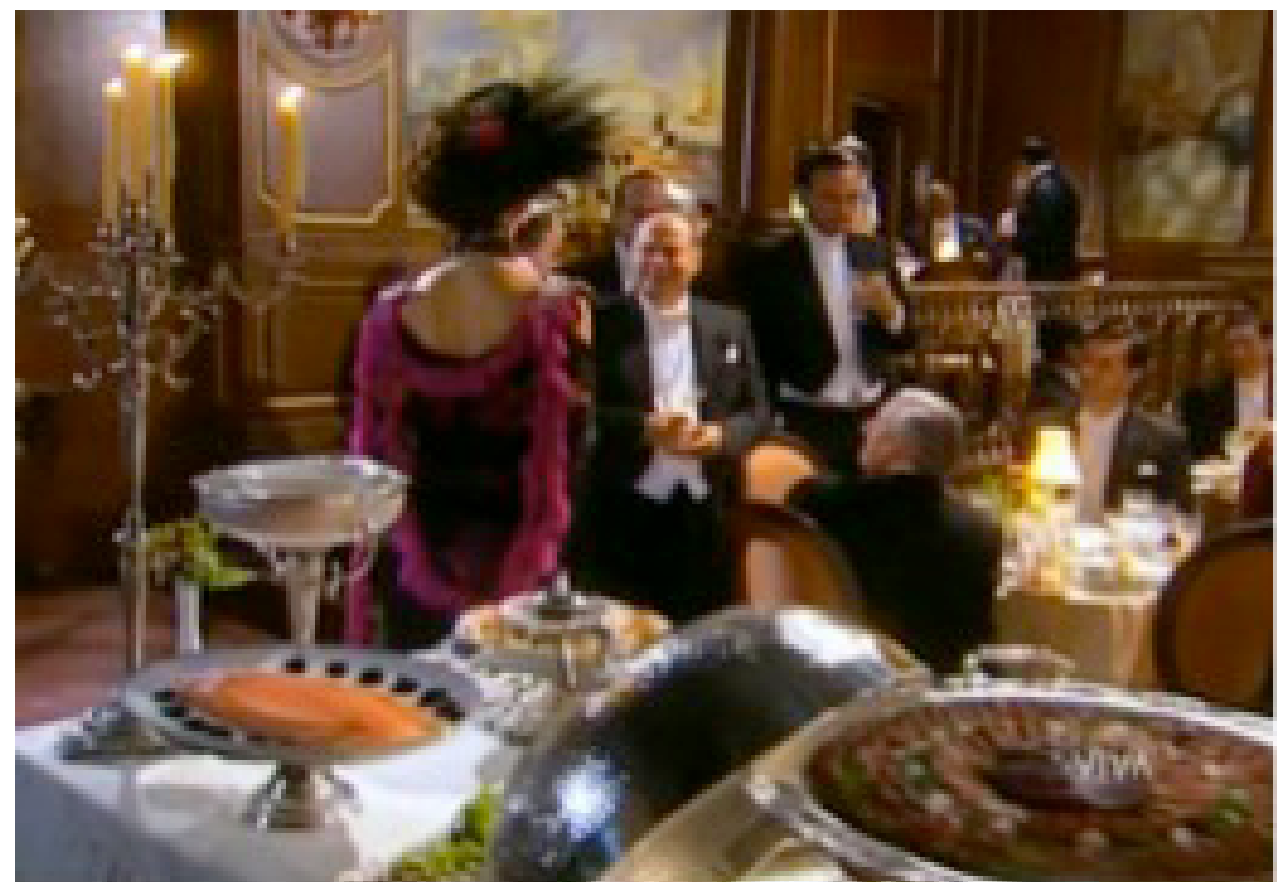

Figura 13: Salão de jantar do navio que vai para Porto Velho (MAD MARIA, 2014)

A câmera passeia não somente entre os detalhes da decoração, mas também entre os detalhes da moda como os fluxos de leques, tecidos de seda, plumas, e os cortes de renda vão compor as personagens femininas. A personagem de Luiza, quando se torna amante do ministro J. de Castro, por exemplo, mesmo muito jovem, prende os cabelos em coque e traz para suas cenas domésticas um ar ligeiramente senhoril. Ao mesmo tempo, essa característica é contrabalançada pelos detalhes transparentes das roupas, o decote que é pronunciado, a saia feita em camadas que permite o "vai e vem" dos tecidos. Até a composição dos vestidos é etérea: pequenas rosas de fita cor de rosa, babados de renda e aplicações em cores pastéis. Trata-se de uma construção de feminilidade etérea que o olho acompanha como fluxo. Luiza aproxima-se desse ideal, como descreve João do Rio (2009) a propósito da figura feminina:

Enfeitiçado, porém, enfeitiçado de gestos, dos adornos, de todas as belezas inúmeras e envolventes de cada mulher [...] como que eleva a símbolo de perdição, o gesto sedutor, as bocas sangrentas e os sorrisos castos, as cabeleiras leves e os olhos luminosos dessas criaturas postas no mundo para que todo o esforço do homem tivesse como causa primária e causa final o seu hipotético amor. (p. 137). 


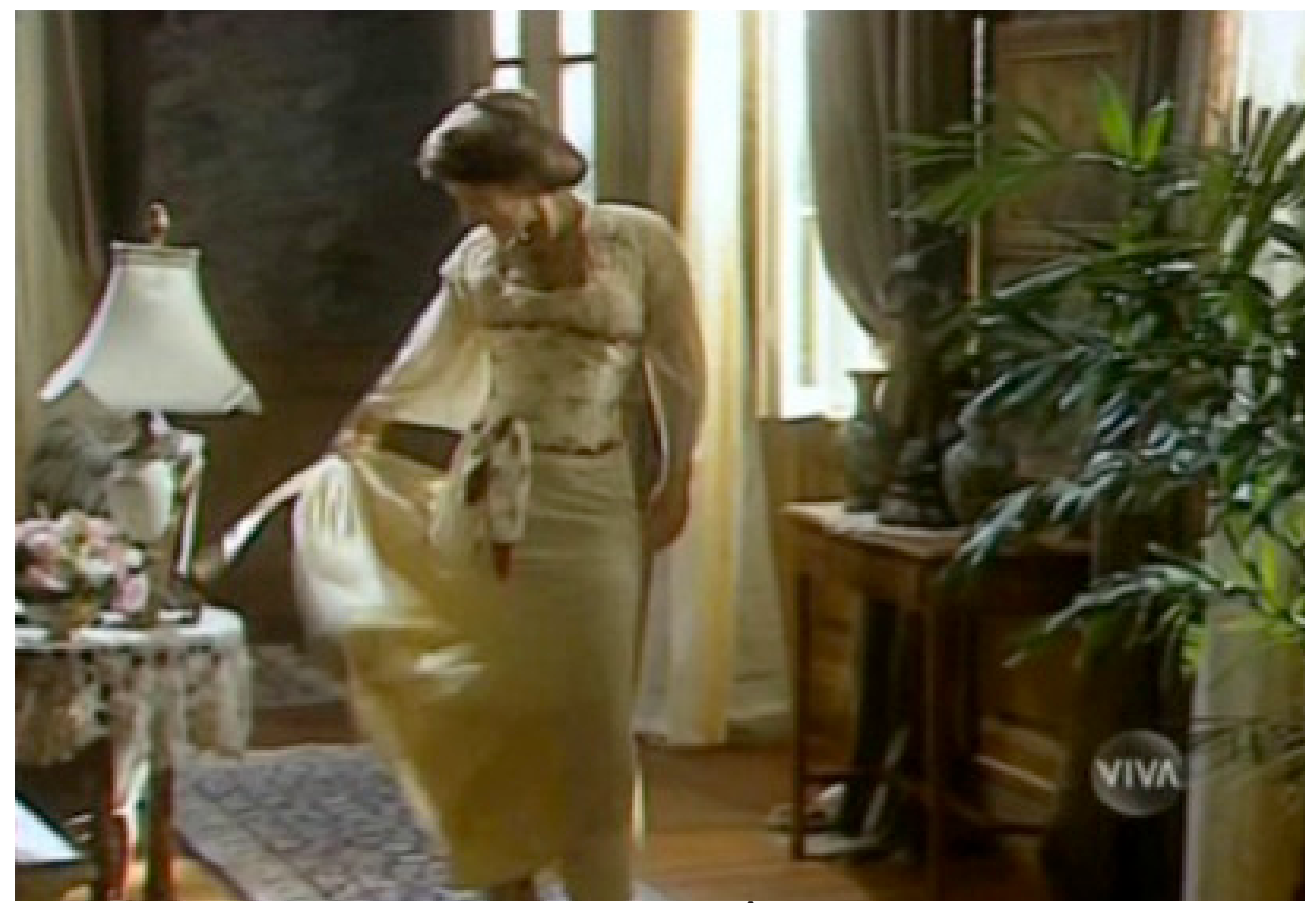

Figura 14: Luiza em sua nova residência (MAD MARIA, 2014)

Outro look estilo belle époque, ainda que mais sofisticado e estilizado, é o de Consuelo. Aqui também o olho pode deslizar por entre detalhes etéreos e esvoaçantes. Os elementos utilizados na época como o imenso chapéu adornado com uma guirlanda de flores, o vestido branco de gola alta, o corpo de renda, o modelo de cintura marcada e a pequena cauda que acompanha a saia. As golas altas, as mangas compridas e as rendas também são signos dessa moda. Consuelo está com a parte de cima do seu vestido em bordado richilieu, antiga técnica europeia que ficou famosa através do Cardeal Richillieu, na França, e de quem recebeu o seu nome.

Interpondo-se à renda, um vestido vermelho complementa o vestido branco, transformando um modelo um tanto sóbrio em um modelo de sobriedade sofisticada e ligeiramente juvenil.

É interessante também ressaltar a construção da glamourização do olhar sobre a moda da época. O figurino das protagonistas não respeita formalmente o padrão histórico. O espartilho em S, comum da época, é desconsiderado. Tal 
espartilho levantava os seios e empurrava o quadril para trás, delineando a figura feminina de outra maneira. O espartilho recebeu o apelido de "peito de pombo", justamente por causa da deformação do corpo. Ainda que o Brasil recebesse essa moda em atraso, percebe-se uma estilização e recriação, de modo a trazer o corpo próximo à contemporaneidade. As roupas parecem de época, mas o corpo se move e age da maneira contemporânea. Podemos supor que, se o espartilho fosse usado, teríamos a visão de um corpo feminino deturpado, estranha ao telespectador do século XXI.

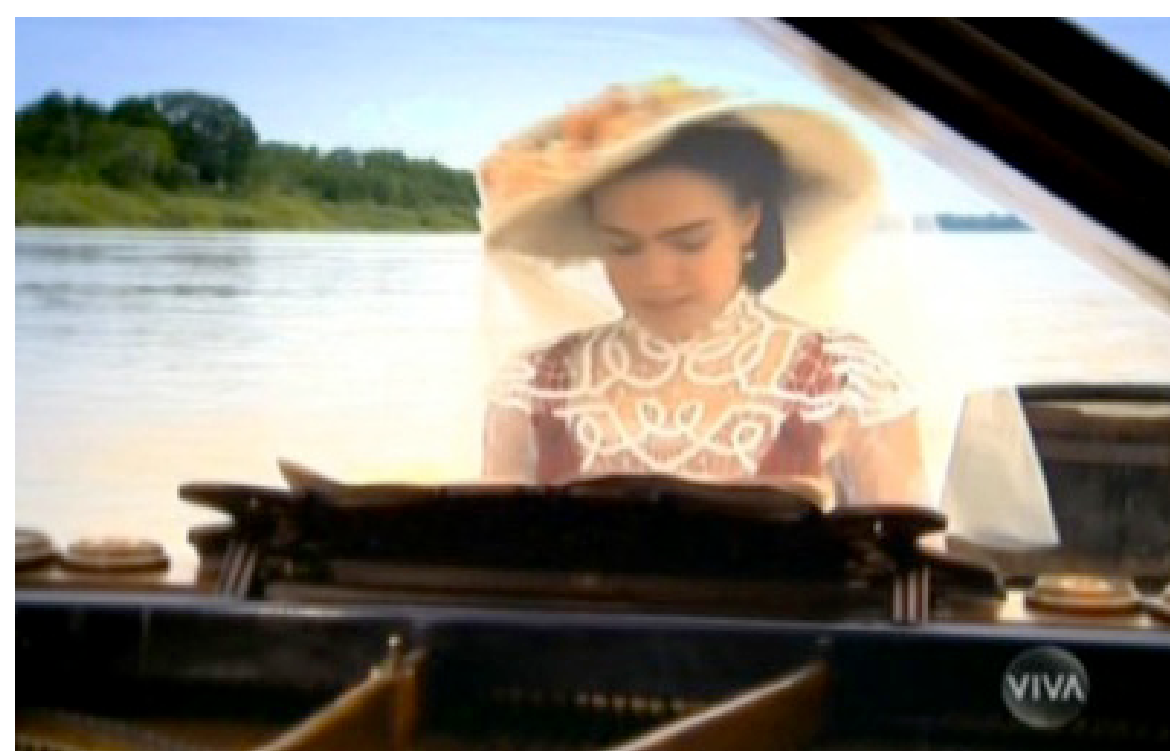

Figura 15: Consuelo e o piano (MAD MARIA, 2014)

\section{Comentários finais}

Como observou Arlindo Machado (1990), a natureza da imagem eletrônica da televisão, sobretudo aquela de baixa definição, tende a se configurar à maneira metonímica, em que a parte e o fragmento valeriam pelo todo. O olho sonda, perscruta e tateia por saltos os pequenos elementos luminosos, de modo a completar a figura inteira.

Em Mad Maria existiria uma coincidência, inclusive temática, com essa natureza da imagem eletrônica: os detalhes dos brilhos, das rendas, dos voils, das pratarias e dos cristais da belle époque. Dentro desse contexto, recorrer aos escritos 
de João do Rio é como olhar através das lentes do "cinematographo", cinema das origens, através do qual os detalhes podem ser disseminados ao fluxo do olhar.

Se esse olhar pode estar presente em Mad Maria, no entanto, um outro olhar, que é dissolvido pelas longas sequências nítidas e contínuas, também está presente. Ora, a implantação do sistema digital e o surgimento da TV de alta definição (HDTV), que consistiu em um aumento no número de linhas verticais e horizontais, permitiu maior qualidade das imagens-paisagens. Ainda que essas imagens possam nos remeter às composições impressionistas, o telespectador de 2005 está se orientando em direção à continuidade e da linearização.

A glamourização dos recursos expressivos realizada pela direção de arte também pode ser compreendida como um processo em direção que é contínuo e homogêneo. Para que esse produto televisivo continue sendo capaz de atender diversos públicos e ainda manter um padrão de exportação, garante-se um imaginário de ambientação e vestuário que possa estar próximo ao estereótipo. Ora, se por um lado o olho do telespectador pode ir captando aqui e ali, como dissemos, vestígios cintilantes de uma belle époque, por outro lado, trata-se de uma recriação estetizada do romance de Márcio de Souza. E a própria belle époque torna-se a imagem da imagem da belle époque.

Seria importante continuar esta discussão no contexto do diálogo entre televisão e cinema. A televisão das origens com seus programas de variedades, suas antigas telenovelas sem recursos sofisticados de direção de arte, repletas de cortes e fragmentos, assim como um primeiro cinema, podem ser vistos como um imenso mosaico visual que só recebem significação a partir da síntese de quem olha. Ao mesmo tempo, a evolução da imagem na televisão equiparou-a a qualidade do cinema sob vários aspectos. Como observa Adalberto Müller (2013) a partir do pensamento de Arlindo Machado:

O processo de narrativização é também o processo de industrialização, que estatiza os produtos e processos de produção, estabelecendo a de trabalho (roteirista, cinegrafista, diretor, ator) para melhor submeter 0 cinema ao processo do capital. (p. 193). 
Acrescentaríamos aí também, dentro deste processo de narração, a complexidade da direção de arte, que se compõe hoje não somente por cenógrafos e figurinistas, mas por designers gráficos, fotógrafos, artistas plásticos, grafiteiros, entre outros, dependendo das especificidades de cada produção.

Ao mesmo tempo, seria importante nessa futura discussão apontar para as possibilidades criativas que a televisão pode estabelecer com o cinema a partir do hibridismo do olhar que tateia e o olhar que mergulha no fluxo contínuo. 


\section{Referências}

BRAGA, J. L. Mediatização como processo interacional de referência. In: MÉDOLA, A.S.D.; ARAÚJO, D. C.; BRUNO, F. (Orgs.). Imagem, visibilidade e cultura midiática (Livro da XV Compós). Porto Alegre: Sulina, 2007.

CRARY, J. Técnicas do observador: visão e modernidade no século XIX. Rio de Janeiro: Contraponto, 2012.

COUCHOT, E. Images de I'optique au Numerique. Paris, França: Editions Hermès, 1988.

GUNNING, T. O retrato do corpo humano: a fotografia, os detetives e os primórdios do cinema. In: CHARNEY, L.; SCHWARTZ, V. (Orgs.). O cinema e a invenção da vida moderna. São Paulo: Cosac Naify, 2001.

MACHADO, A. A Arte do Vídeo. São Paulo: Brasiliense, 1990. . Pré-cinemas \& Pós Cinemas. Campinas: Papirus, 2002.

MAD MARIA. Direção de Ricardo Waddington. Roteiro de Benedito Ruy Barbosa. Rio de Janeiro: Canal Viva, 2014 (reexibição).

MONET, C. Campo de Papoulas. Disponível em: <http://www.jackygallery.com/ images/Poppy\%20Field\%20in\%20Argenteuil\%20by\%20Claude\%20Monet\%20 OSA063.jpg >. Acesso em: 25 nov. 2015.

MÜLLER, A. João do Rio e o cinematographo: primeira modernidade literária e primeiro cinema. Revista Eletrônica Itinerários, Araraquara, n. 36, 2013. 
RIO, J. A alma encantadora das ruas. São Paulo: Companhia de Bolso, 2008. . Cinematógrafo. Rio de Janeiro: Academia Brasileira de Letras, 2009.

TURNER, W. Fort Vimieux. Disponível em:<https://upload.wikimedia.org/ wikipedia/commons/thumb/1/1d/Turner_-_Fort_Vimieux.jpg/640px-Turner_-_ Fort_Vimieux.jpg>. Acesso em: 25 nov. 2015.

submetido em: 23 jul. 2015 | aprovado em: 14 set. 2015 